\title{
Using NOTES to salvage a misdeployed lumen-apposing metal stent during an endoscopic ultrasound-guided gastroenterostomy
}

Endoscopic ultrasound (EUS)-guided gastroenterostomy with placement of a lumen-apposing metal stent (LAMS) is a minimally invasive endoscopic option for patients with gastric outlet obstruction (GOO) [1-3]. The procedure involves accessing the small bowel and deploying a LAMS to connect the stomach to the small bowel. In rare cases, stent misdeployment results in one end of the stent being deployed outside the targeted lumen. When wire access is preserved, the misdeployed stent can be successfully salvaged by placing a fully covered selfexpanding metal stent (FCSEMS) through the misdeployed LAMS using fluoroscopy guidance [4]. In this report, we present a case of a misdeployed LAMS without preserved wire access that was salvaged using the natural orifice transluminal endoscopic surgery (NOTES) technique.

A 56-year-old woman with cholangiocarcinoma presented with recurrent GOO after enteral stenting. EUS-guided gastroenterostomy was performed. An echoendoscope was advanced into the stomach. The jejunum was identified endosonographically and accessed with a 19-gauge needle. A wire was advanced through the needle and coiled in the jejunal lumen. A LAMS with cautery (Axios; Boston Scientific, Natick, Massachusetts, USA) was then deployed over the wire. Relook endoscopy revealed that the distal end of the LAMS was positioned in the peritoneum, likely due to dislodgement from retraction prior to deploying the proximal flange in the setting of adhesions.

A double-channel endoscope was advanced into the stomach and into the lumen of the LAMS. The jejunal loop was visualized and grasped with a rat-tooth forceps. A needle-knife catheter was advanced through the second endoscope channel and was used to access the jejunal loop (> Fig.1). A wire was advanced through the catheter and coiled in the jejunum. A through-the-scope FCSEMS

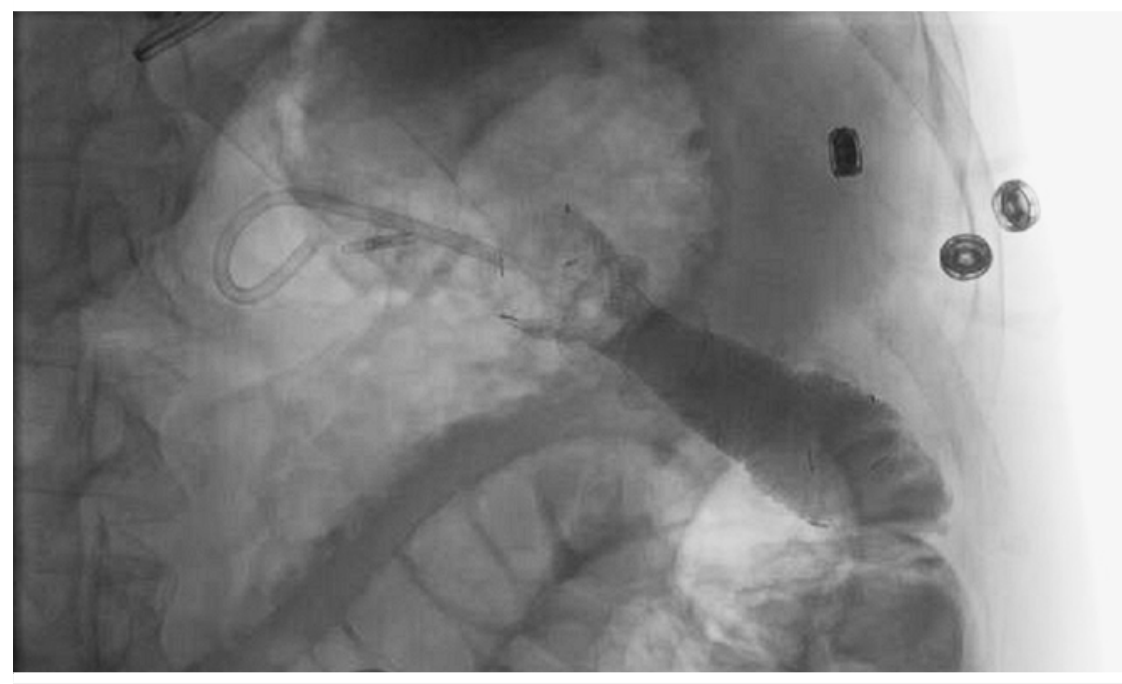

- Fig. 1 Fluoroscopy imaging showing a transgastric bridging fully covered esophageal stent placed in the lumen-apposing metal stent and terminating in the small bowel.

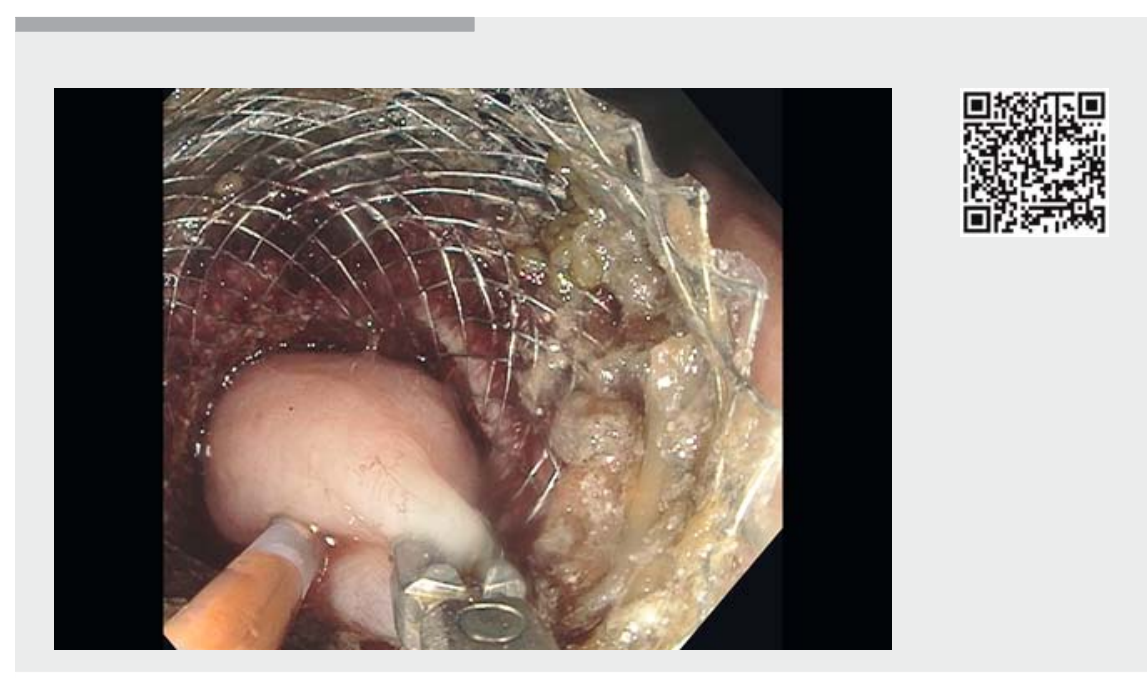

$\checkmark$ Video 1 The natural orifice transluminal endoscopic surgery (NOTES) technique is used to salvage a lumen-apposing metal stent by placing a bridging through-the-stent fully covered esophageal stent.

(Esophageal TTS; Taewoong Medical, Seoul, South Korea) was deployed through the LAMS with the distal end in the jejunum and the proximal end in the stomach ( $\triangleright$ Video 1 ). Contrast confirmed the stent position. At 1-month follow-up, the patient continues to tolerate an oral diet.

The NOTES technique is a feasible and safe way to salvage a misdeployed LAMS in patients undergoing EUS-guided gastroenterostomy. 


\section{Competing interests}

M. Kahaleh has received grants from Boston Scientific, Olympus, Cook Medical and Gore Medical.

The Authors

Amy Tyberg, Monica Saumoy, Michel Kahaleh Division of Gastroenterology and Hepatology, Weil Cornell Medical, New York, New York, USA

Corresponding author

Michel Kahaleh, MD

Division of Gastroenterology \& Hepatology, Weill Cornell Medical College, New York, NY 10021, USA

Fax: +1-646-962-0110

mkahaleh@gmail.com

\section{References}

[1] Itoi T, Itokawa F, Uraoka T et al. Novel EUSguided gastrojejunostomy technique using a new double-balloon enteric tube and lumen-apposing metal stent (with videos). Gastrointest Endosc 2013; 78: 934 - 939

[2] Khashab MA, Kumbhari V, Grimm IS et al. EUS-guided gastroenterostomy: the first U.S. clinical experience (with video). Gastrointest Endosc 2015; 82: 932 - 938

[3] Tyberg A, Perez-Miranda M, Sanchez-Ocana $R$ et al. Endoscopic ultrasound-guided gastrojejunostomy with a lumen-apposing metal stent: a multicenter, international experience. Endosc Int Open 2016; 4: E276-E281

[4] Tyberg A, Zerbo S, Barthet M et al. A novel technique for salvaging a dislodged lumenapposing metal stent during creation of an endoscopic gastrojejunostomy. Gastrointest Endosc 2016; 83: 254

\section{Bibliography}

DOI https://doi.org/10.1055/s-0043-113551

Published online: 18.7.2017

Endoscopy 2017; 49: 1007-1008

(c) Georg Thieme Verlag KG

Stuttgart · New York

ISSN 0013-726X

\section{ENDOSCOPY E-VIDEOS}

https://eref.thieme.de/e-videos

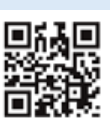

Endoscopy E-Videos is a free access online section, reporting on interesting cases and new techniques in gastroenterological endoscopy. All papers include a high quality video and all contributions are freely accessible online.

This section has its own submission website at https://mc.manuscriptcentral.com/e-videos 